\title{
Potent Inhibitory Activity of HSR-6071, a New Antiallergic Agent, on Passive Cutaneous Anaphylaxis (PCA)
}

\author{
Eiichi MAKINO, Tetsuo OHASHI, Hiromi TAKAHASHI, Hideo KATO, \\ Yasuo ITO, Hiroichi NAGAl ${ }^{1}$, Akihide KODA ${ }^{1}$ and Hiroshi AZUMA² \\ Central Research Laboratories, Hokuriku Seiyaku Co., Ltd., \\ Katsuyama, Fukui 911. Japan \\ ${ }^{1}$ Department of Pharmacology, Gifu Pharmaceutical University, Gifu 502, Japan \\ ${ }^{2}$ Department of Medicinal Chemistry, Institute for Medical and Dental Engineering. \\ Tokyo Medical and Dental University, Chivoda-ku, Tokyo 101. Japan
}

Accepted September 22, 1989

\begin{abstract}
Antiallergic effects of 6-(1-pyrrolidinyl)- $\mathrm{N}$ - (1H-tetrazol-5-yl)-2-pyrazinecarboxamide (HSR-6071), a newly synthesized agent, were investigated. The 48-hr homologous passive cutaneous anaphylaxis (PCA) in rats was inhibited in a dose-dependent manner by i.v. and p.o. administration of the agent (ED50 $=0.0096$ $\mathrm{mg} / \mathrm{kg}$ and $0.18 \mathrm{mg} / \mathrm{kg}$, respectively). The $\mathrm{lgE}$-mediated histamine release from rat peritoneal exudate cells was inhibited by HSR-6071, with an IC50 of $4.6 \times 10^{-10}$ M. Regarding the non-immunological histamine release, HSR-6071 inhibited compound 48/80-induced, but not A23187-induced and spontaneous histamine release. On the other hand, an increase in vascular permeability induced by histamine, serotonin and bradykinin was unaffected by HSR-6071 in doses sufficient to inhibit PCA. In addition, the contractile responses of isolated guinea pig ileum to histamine, acetylcholine and serotonin were also unaffected by the agent even in a high concentration of $10^{-4} \mathrm{M}$. These results indicate that HSR-6071 possesses a potent antiallergic activity and that the inhibition of PCA by HSR-6071 may be due to the suppression of chemical mediators release from mast cells.
\end{abstract}

Disodium cromoglycate (DSCG), an agent which inhibits histamine release induced by IgE-antibody, has been clinically used for allergic diseases $(1-3)$, particularly for bronchial asthma. However, the lack of absorption of this drug through the gastrointestinal tract has prevented its use by the oral route. Such being the case, studies have been made to develop an orally effective drug (4). First. tranilast (5-7) was developed as an orally effective antiallergic agent in Japan. Later, a number of agents have been developed (813) and used for the treatment of asthma.

We have studied the antiallergic activity of pyrazine derivatives in order to develop a new antiallergic drug possessing high potency and less toxicity. As a result, we have discovered satisfactory properties in 6-(1-pyrrolidinyl)$\mathrm{N}$-(1H-tetrazol-5-y!)-2.-pyrazinecarboxamide (HSR-6071) (Fig. 1). In the present paper.

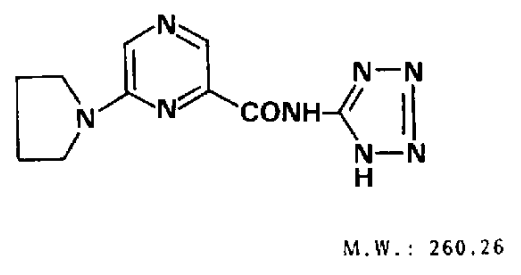

Fig. 1. Chemical structure of HSR-6071.

the inhibitory effect of HSR-6071 on the IgE-mediated passive cutaneous anaphylaxis (PCA) and the mechanism of the inhibitory action were studied as compared with those of DSCG, amlexanox and ketotifen.

\section{Materials and Methods}

Animals: Male Wistar rats and male Hartley guinea pigs were purchased from Japan SLC Inc. (Hamamatsu, Japan) and housed in an air-conditioned room at $24 \pm 2{ }^{\circ} \mathrm{C}$ and fed the 
usual laboratory diet and water ad libitum as provided.

Materials: The following drugs were used: HSR-6071, tranilast, MY-1250 (active metabolite of repirinast), azelastine and oxatomide (all of them were synthesized at Hokuriku Seiyaku Co., Ltd.), amlexanox (Takeda), repirinast (Mitsubishi Yuka). DSCG (Star) and ketotifen (Resfar). HSR-6071 and amlexanox were dissolved in $0.1 \mathrm{~N} \mathrm{NaOH}$ and neutralized by $0.1 \mathrm{~N} \mathrm{HCl}$ and difuted with physiological saline for i.v. administration or with distilled water for the in vitro studies to the required concentrations. Tranilast was dissolved in $1 \%(\mathrm{~W} / \mathrm{v}) \mathrm{NaHCO}_{3}$. DSCG, MY1250 and ketotifen were dissolved in physiological saline or distilled water. For oral administration, all these compounds were suspended in $0.5 \%$ sodium carboxymethylcellulose solution (CMC), except for DSCG and ketotifen, which were dissolved in distilled water.

Antigen: Ascaris extract coupled with the 2,4-dinitrophenyl group (DNP-As) was prepared by the method of Tada and Okumura (14). The protein content of DNP-As was determined to be $40 \%$ by a Bio Rad protein assay kit (Bio Rad).

Preparation of rat anti-DNP-As serum: Anti-DNP-As serum containing lgE antibody was prepared by the method of Tada and Okumura (14) in male Wistar rats weighing 280 to $330 \mathrm{~g}$. The PCA titer of the antiserum was estimated as 1:256 by 48-hr PCA in rats.

48-hr homologous passive cutaneous anaphylaxis (PCA): The PCA induced by antiDNP-As serum containing $\lg E$ antibody was measured by the procedure described previously (6) in male Wistar rats weighing 180 to $220 \mathrm{~g}$. The intensity of the response was evaluated by assaying the amount of extravasated dye according to the method of Katayama et al. (15). The ED50 value was calculated according to the method of Litchfield-Wilcoxon.

Increase in vascular permeability induced by histamine, serotonin or bradykinin in rats: Male Wistar rats weighing 180 to $220 \mathrm{~g}$ were used. The cutaneous reaction was induced by intradermal injection of $20 \mu \mathrm{g} / \mathrm{site}$ of histamine dihydrochloride (Nacalai Tesque), 0.2 $\mu \mathrm{g} / \mathrm{site}$ of serotonin creatinin sulfate (Wako) or $5 \mu \mathrm{g} /$ site of bradykinin (Sigma) immediately after an i.v. injection of $0.5 \mathrm{ml} / \mathrm{rat}$ of $1 \%$ ( $w / v$ ) Evans blue (Wako). The animals were killed by stunning $30 \mathrm{~min}$ after the injection of inducers. The amount of extravasated dye was determined as described above.

Contractile responses induced by histamine, acetylcholine and serotonin in isolated guinea pig ileum: An approximately $20-\mathrm{mm}$ strip of isolated guinea pig ileum was suspended vertically under a $0.5 \mathrm{~g}$ load in an organ bath containing $10 \mathrm{ml}$ of Locke-Ringer solution maintained at $30^{\circ} \mathrm{C}$ and bubbled with a gas mixture of $95 \% \mathrm{O}_{2}$ and $5 \% \mathrm{CO}_{2}$. Changes in isometric tension were recorded by means of a force-displacement transducer. The contraction induced by histamine (5.4x $\left.10^{-7} \mathrm{M}\right)$, acetylcholine $\left(5.5 \times 10^{-7} \mathrm{M}\right)$ or serotonin $\left(2.5 \times 10^{-6} \mathrm{M}\right)$, which produced the submaximal contraction, was measured in the absence and then in the presence of various concentrations of test compounds. The incubation with test compound continued for $5 \mathrm{~min}$ before addition of an agonist. The percentage of inhibition was calculated by comparing the responses with or without test compound.

IgE-mediated histamine release from rat peritoneal exudate cells (PEC): PEC containing mast cells were collected from the peritoneal cavity of male Wistar rats weighing 350 to $450 \mathrm{~g}$ and suspended in HEPES buffer (1.0 mM HEPES, $137 \mathrm{mM} \mathrm{NaCl}, 2.7 \mathrm{mM} \mathrm{KCl}$, $1.0 \mathrm{mM} \mathrm{CaCl}, 1.0 \mathrm{mM} \mathrm{Na} \mathrm{HPO}_{4}, 5.6 \mathrm{mM}$ glucose, 10 units $/ \mathrm{ml}$ heparin, $0.3 \%(\mathrm{w} / \mathrm{v})$ bovine serum albumin, $\mathrm{pH} 7.2$ ). The mast cells were passively sensitized with anti- DNP. As serum under gentle agitation for $2 \mathrm{hr}$ at $37^{\circ} \mathrm{C}$ according to the method described previously (7). The sensitized cells (about $1 \times$ $10^{5}$ mast cells $/ \mathrm{ml}$ ) were rinsed and suspended in HEPES buffer, preincubated at $37^{\circ} \mathrm{C}$ for 10 min, and then incubated with $10 \mu \mathrm{g}$ of DNP. As for the following $20 \mathrm{~min}$. The total volume of the reaction medium was $1 \mathrm{~m} !$. Test compounds were added 1 min prior to the antigen challenge. The amount of histamine released was assayed by the fluorometric method of Shore et al. (16).

Compound 48/80- or A23187-induced histamine release from rat PEC: PEC from normal rats $\left(1 \times 10^{5}\right.$ mast cells $\left./ \mathrm{ml}\right)$ were pre- 
incubated for $10 \mathrm{~min}$ at $37^{\circ} \mathrm{C}$ and challenged with compound $48 / 80(0.01$ to $1.0 \mu \mathrm{g} / \mathrm{ml})$ or A23187 $(0.05$ to $1.0 \mu \mathrm{g} / \mathrm{ml})$. After termination of the following 20 min-incubation, the amount of histamine released was assayed. The test compounds were added into the reaction mixture $1 \mathrm{~min}$ prior to the challenge of compound $48 / 80$ or A23187.

Statistical analysis: Results are expressed as the mean and standard error. Statistical significance was determined by Student's $t$-test.

\section{Results}

Effect on 48-hr homologous PCA in rats: The amount of extravasated dye resulting

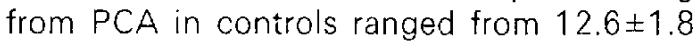
to $23.5 \pm 4.6 \mu \mathrm{g} / \mathrm{site}$ in the different experiments. In order to find out the proper pretreatment time with HSR-6071, $0.03 \mathrm{mg} / \mathrm{kg}$, i.v. or $1 \mathrm{mg} / \mathrm{kg}$, p.o. of HSR-6071 was given at varying times before the antigen challenge. As shown in Fig. 2, the most potent inhibition of PCA was observed when this agent was administered i.v. just before or p.o. $5 \mathrm{~min}$ before the antigen challenge. In both i.v. and p.a. administration of HSR-6071, the inhibitory activity decreased with a prolongation of the pretreatment time before the antigen challenge, and inhibition became insignificant at 30 min-pretreatment time for i.v. administration and at $120 \mathrm{~min}$-pretreatment time for the p.o. route. Table 1 shows the inhibitory effects of HSR-6071 and known antiallergic agents on $48 \mathrm{hr}$ homologous PCA. All agents tested produced a dosedependent inhibition of PCA. The potency was compared in terms of ED50 (dose producing $50 \%$ inhibition of PCA) values and their ratio. Among the agents tested, HSR6071 produced the most potent inhibition both in i.v. and in p.o. administration.

Effects on the vascular permeabilities induced by histamine, serotonin and bradykinin in rats: Intradermal injection of histamine $(20 \mu \mathrm{g} / \mathrm{site})$, serotonin $(0.2 \mu \mathrm{g} / \mathrm{site})$ or bradykinin ( $5 \mu \mathrm{g} / \mathrm{site}$ ) caused an increase in vascular permeability. which was estimated by the amount of extravasated dye. The dose of stimulants was chosen to produce nearly the same amount of extravasated dye as in the case of PCA. HSR-6071 and DSCG at i.v. doses sufficient to inhibit PCA failed to modify the increased vascular permeability caused by histamine, serotonin and bradykinin (Table 2). In contrast, ketotifen inhibited the cutaneous reactions at the same dose to inhibit PCA. The mode of inhibition with the agent was dose-dependent. The most potent inhibition with ketotifen was observed in the histamine-induced cutaneous reaction.

Effects on the contractile responses in-

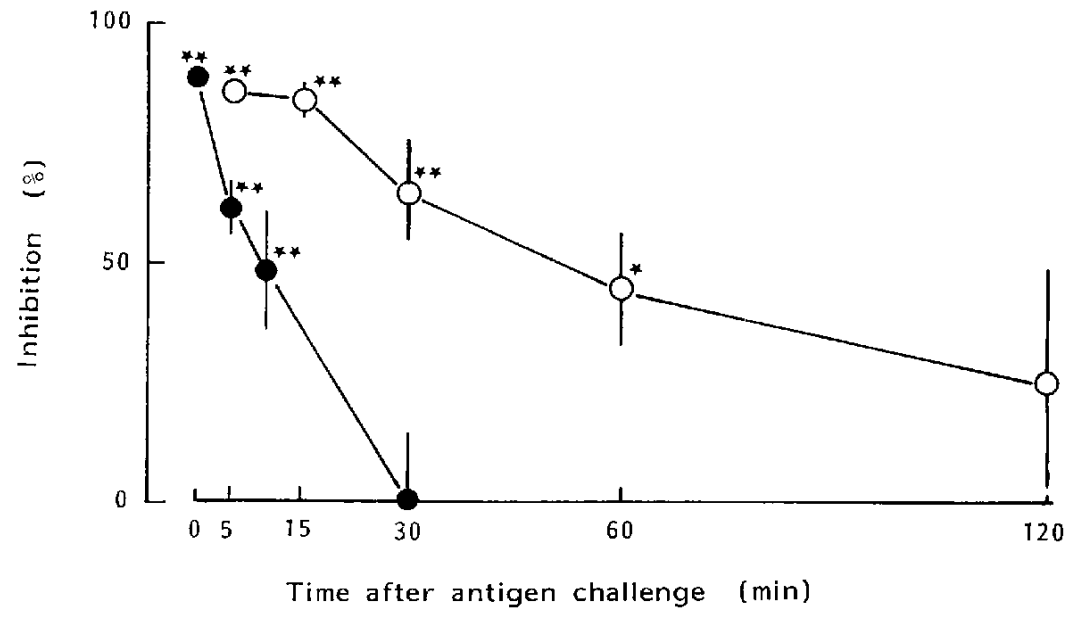

Fig. 2. Time course for the inhibitory effect of HSR-6071 on PCA in rats. The agent was given i.v. or p.o. (O) at various times before the antigen challenge. Each point represents the mean $\pm S . E . M$. of 7 to 8 experiments. $\star$ and $\star \star$ : Statistically significant difference from the control at $P<0.05$ and $P<$ 0.01 , respectively 
Table 1. Inhibitory effect of HSR-6071 and reference antiallergic drugs on 48-hr homologous PCA in rats

\begin{tabular}{llccr}
\hline Compound & Route & $\begin{array}{c}\text { Time } \\
(\mathrm{min})\end{array}$ & $\begin{array}{c}\text { ED50 } \\
(\mathrm{mg} / \mathrm{kg})\end{array}$ & Dose ratio \\
HSR-6071 & p.o. & 5 & 0.18 & 1 \\
DSCG & i.v. & 0 & 0.0096 & 1 \\
& p.o. & 30 & $>100$ & $>555.6$ \\
Tranilast & i.v. & 0 & 0.39 & 40.6 \\
& p.o. & 30 & 67 & 372.2 \\
Amlexanox & i.v. & 0 & 20 & 2083.3 \\
& p.o. & 5 & 0.79 & 4.4 \\
Repirinast & i.v. & 0 & 0.012 & 1.3 \\
(MY-1250) & p.o. & 30 & 42 & 2.33 .3 \\
Ketotifen & i.v. & 0 & 0.046 & 4.8 \\
& p.o. & 60 & 0.48 & 2.7 \\
Azelastine & i.v. & 0 & 0.23 & 24.0 \\
Oxatomide & p.o. & 60 & 3.7 & 20.6 \\
\hline
\end{tabular}

Each drug was given i.v. immediately before or p.o. at various times before the antigen challenge. The pretreatment time (Time) for each agent was selected to obtain the most potent activity.

Table 2. Comparison of effects of HSR-6071. DSCG and ketotifen on an increase in vascular permeability induced by exogenous histamine, serotonin and bradykinin in rats

\begin{tabular}{|c|c|c|c|c|c|c|}
\hline \multirow{2}{*}{$\begin{array}{l}\text { Exp. } \\
\text { No. }\end{array}$} & \multirow{2}{*}{ Compound } & \multirow{2}{*}{$\begin{array}{c}\text { Dose } \\
(\mathrm{mg} / \mathrm{kg})\end{array}$} & \multirow{2}{*}{$\begin{array}{l}\text { No. of } \\
\text { rats }\end{array}$} & \multicolumn{3}{|c|}{ Amount of extravasated dye ( $\mu \mathrm{g} / \mathrm{site}$. mean \pm S.E.M.) } \\
\hline & & & & $\begin{array}{l}\text { Histamine } \\
(20 \mu \mathrm{g} / \mathrm{site})\end{array}$ & $\begin{array}{c}\text { Serotonin } \\
(0.2 \mu \mathrm{g} / \mathrm{site})\end{array}$ & $\begin{array}{l}\text { Bradykinin } \\
(5 \mu \mathrm{g} / \mathrm{site})\end{array}$ \\
\hline \multirow[t]{5}{*}{1.} & Control & & 8 & $26.7 \pm 3.0$ & $23.4 \pm 2.8$ & $22.2 \pm 2.8$ \\
\hline & HSR-6071 & 0.03 & 8 & $28.8 \pm 3.2$ & $22.2 \pm 2.7$ & $22.0 \pm 0.7$ \\
\hline & & 0.1 & 7 & $20.8 \pm 1.8$ & $20.1 \pm 3.5$ & $19.8 \pm 1.9$ \\
\hline & & 0.3 & 8 & $28.7 \pm 1.8$ & $25.2 \pm 3.0$ & $24.7 \pm 3.5$ \\
\hline & DSCG & 3 & 8 & $31.8 \pm 4.4$ & $26.3 \pm 3.1$ & $26.0 \pm 3.3$ \\
\hline \multirow[t]{4}{*}{2.} & Control & & 9 & $18.4 \pm 1.8$ & $13.1 \pm 1.4$ & $10.5 \pm 0.8$ \\
\hline & Ketotifen & 0.1 & 7 & $8.7 \pm 0.9^{* *}$ & $9.9 \pm 1.1$ & $10.3 \pm 0.6$ \\
\hline & & 0.3 & 7 & $5.4 \pm 0.9^{* *}$ & $5.8 \pm 0.9^{* *}$ & $7.9 \pm 1.0^{*}$ \\
\hline & & 1 & 7 & $3.5 \pm 0.3^{* *}$ & $6.4 \pm 0.9^{* *}$ & $8.0 \pm 0.4^{* *}$ \\
\hline
\end{tabular}

Test compounds were given i.v. immediately before injections of histamine, serotonin and bradykinin.

* and ${ }^{*}$ : Statistically significant difference from the control at $P<0.05$ and $P<0.01$, respectively.

duced by histamine, acetylcholine and serotonin in isolated guinea pig ileum: Results are summarized in Table 3. Neither histamine-, acetylcholine- nor serotonin-induced con- traction of isolated guinea pig ileum were affected by HSR-6071 and DSCG even at the high concentration of $10^{-4} \mathrm{M}$. On the other hand, ketotifen markedly suppressed the 
Table 3. Comparison of effects of HSR-6071. DSCG and ketotifen on the contractile responses induced by histamine, acetylcholine and serotonin in isolated guinea pig ileum

\begin{tabular}{lcccc}
\hline Compound & $\begin{array}{c}\text { Conc. } \\
(\mathrm{M})\end{array}$ & $\begin{array}{c}\text { Histamine } \\
\left(5.4 \times 10^{-7} \mathrm{M}\right)\end{array}$ & $\begin{array}{c}\text { Inhibition }(\%, \text { mean } \pm \text { S.E.M. }) \\
\left(5.5 \times 10^{-7} \mathrm{M}\right)\end{array}$ & $\begin{array}{c}\text { Serotonin } \\
\left(2.5 \times 10^{-6} \mathrm{M}\right)\end{array}$ \\
\hline HSR-6071 & $10^{-4}$ & $5.7 \pm 1.63$ & $6.7 \pm 1.15$ & $-1.2 \pm 5.76$ \\
DSCG & $10^{-4}$ & $-8.2 \pm 4.08$ & $-0.4 \pm 1.46$ & $2.6 \pm 0.91$ \\
Ketotifen & $10^{-9}$ & $18.7 \pm 2.48$ & $\mathrm{NT}$ & $\mathrm{NT}$ \\
& $3 \times 10^{-9}$ & $37.3 \pm 3.50$ & $\mathrm{NT}$ & $\mathrm{NT}$ \\
& $10^{-8}$ & $82.8 \pm 1.83$ & $\mathrm{NT}$ & $12.0 \pm 7.23$ \\
& $10^{-7}$ & $\mathrm{NT}$ & $\mathrm{NT}$ & $34.5 \pm 8.90$ \\
& $10^{-6}$ & $\mathrm{NT}$ & $25.1 \pm 3.90$ & $62.7 \pm 2.58$ \\
& $10^{-5}$ & $\mathrm{NT}$ & $66.7 \pm 2.24$ & $\mathrm{NT}$ \\
& $10^{-4}$ & $\mathrm{NT}$ & $99.3 \pm 0.67$ & $\mathrm{NT}$ \\
\hline
\end{tabular}

A segment of isolated guinea pig ileum was suspended with $0.5 \mathrm{~g}$ tension in Locke-Ringer solution maintained at $30 \pm 1^{\circ} \mathrm{C}$. The contractile response of the tissue was recorded isometrically. Test compounds were added $5 \mathrm{~min}$ before the addition of agonists. Each value represents the mean \pm S.E.M. of 3 to 5 experiments. NT: Not tested.

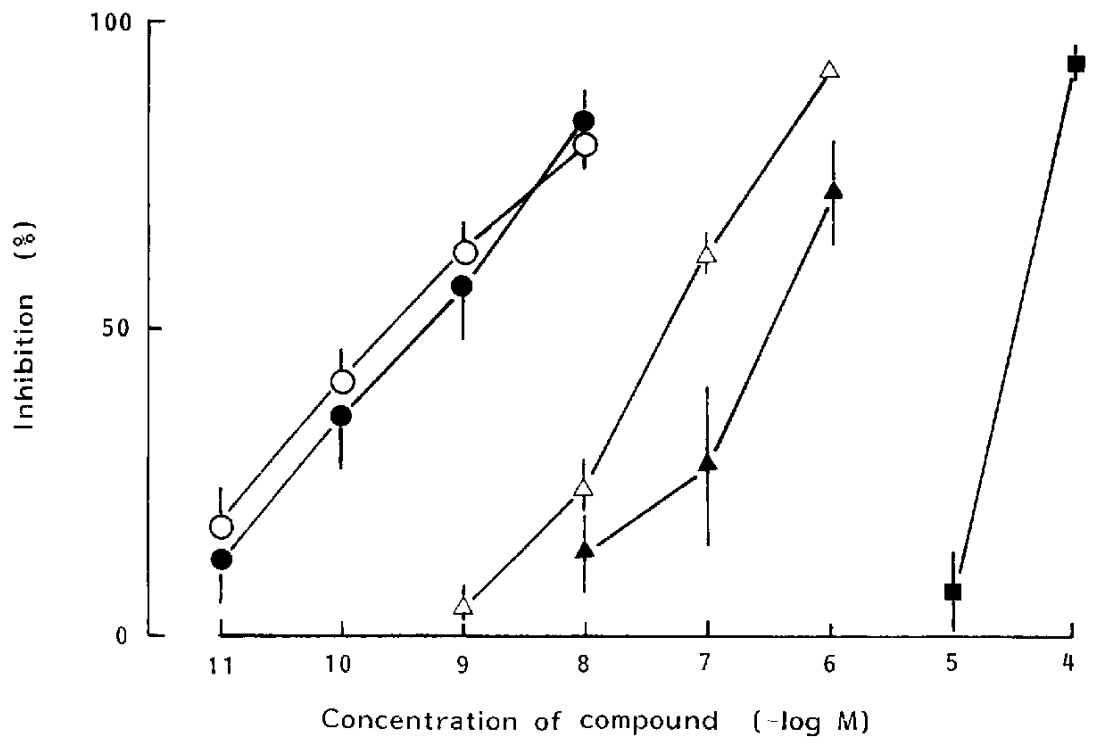

Fig. 3. Inhibitory effect of HSR-6071 ( $)$ DSCG ( $\mathbf{\Delta})$, tranilast ( $\mathbf{\square})$, amlexanox (O) and MY-1250 $(\triangle)$ on the $\mathrm{lgE}$-mediated histamine release from rat peritoneal mast cells. Peritoneal exudate cells $\left(1 \times 10^{6}\right.$ mast cells $/ \mathrm{ml}$ ) were passively sensitized with rat anti-DNP-As serum. Test compounds were added in the reaction mixture 1 min before the challenge with DNP-As. Each point represents the mean \pm S.E.M. of 3 to 5 experiments. Total histamine contents: $2.01 \pm 0.11 \mu \mathrm{g} / 10^{5}$ mast cells. Spontaneous histamine release: $2.7 \pm 0.2 \%$. Antigen-induced histamine release: $22.3 \pm 1.5 \%$.

contractile responses induced by histamine, acetylcholine and serotonin, with IC50 values of $4.2 \times 10^{-9}, 4.5 \times 10^{-6}$ and $3.2 \times 10^{-7} \mathrm{M}$, respectively.
Effect on the IgE-mediated histamine release from rat PEC: The challenge of DNPAs caused $22.3 \pm 1.5 \%$ of histamine release from PEC sensitized passively with the $\operatorname{IgE}$ 
antibody. The IgE antibody-mediated histamine release was inhibited by all compounds tested except for ketotifen in a concentrationdependent manner (Fig. 3). The IC50 values of HSR-6071, amlexanox, MY-1250, tranilast and DSCG were calculated as $4.6 \times 10^{-10}$, $2.0 \times 10^{-10}, 2.1 \times 10^{-8}, 3.2 \times 10^{-5}$ and $3.2 \times$ $10^{-7} \mathrm{M}$, respectively. In contrast, the histamine release was scarcely affected by ketotifen at concentrations of $10^{-6}$ and $10^{-5} \mathrm{M}$.

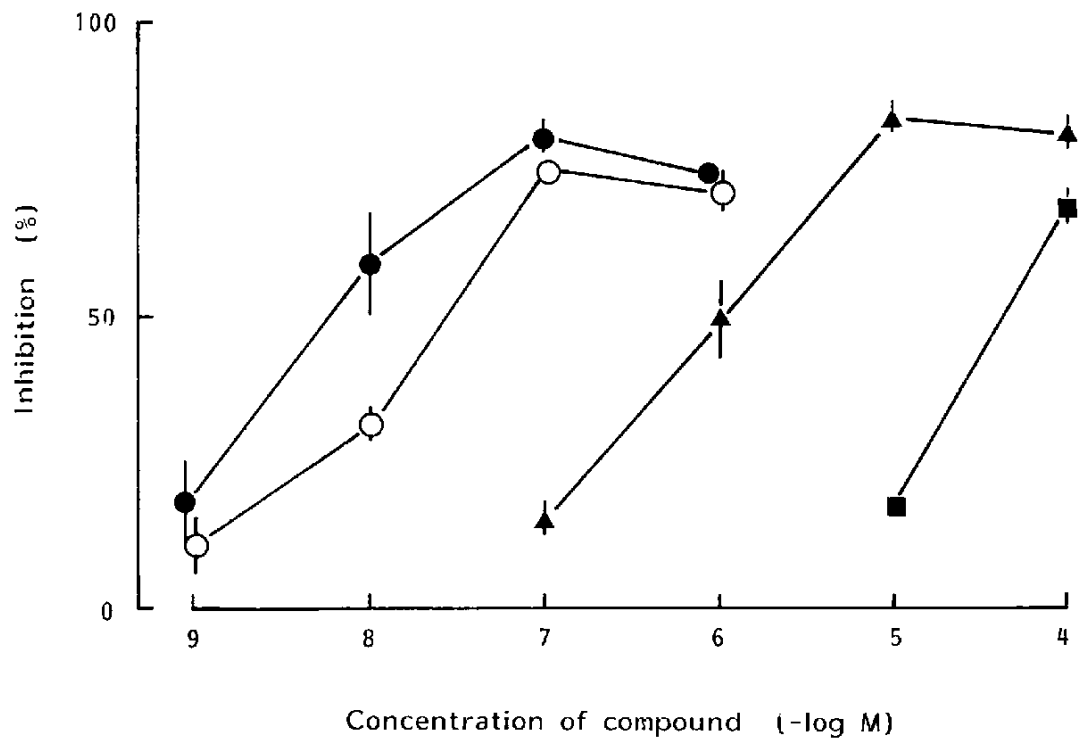

Fig. 4. Inhibitory effect of HSR-6071 (O), DSCG (A), tranilast $(\boldsymbol{\square})$ and amlexanox (O) on compound $48 / 80(0.1 \mu \mathrm{g} / \mathrm{ml})$-induced histamine release from rat peritoneal exudate cells. Each point represents the mean \pm S.E.M. of 3 to 4 experiments. Total histamine contents: $2.35 \pm 0.14 \mu \mathrm{g} / 10^{5}$ mast cells. Compound $48 / 80(0.1 \mu \mathrm{g} / \mathrm{ml})$-induced histamine release: $25.0 \pm 0.6$ to $34.1 \pm 2.7 \%$ in the different experiments.

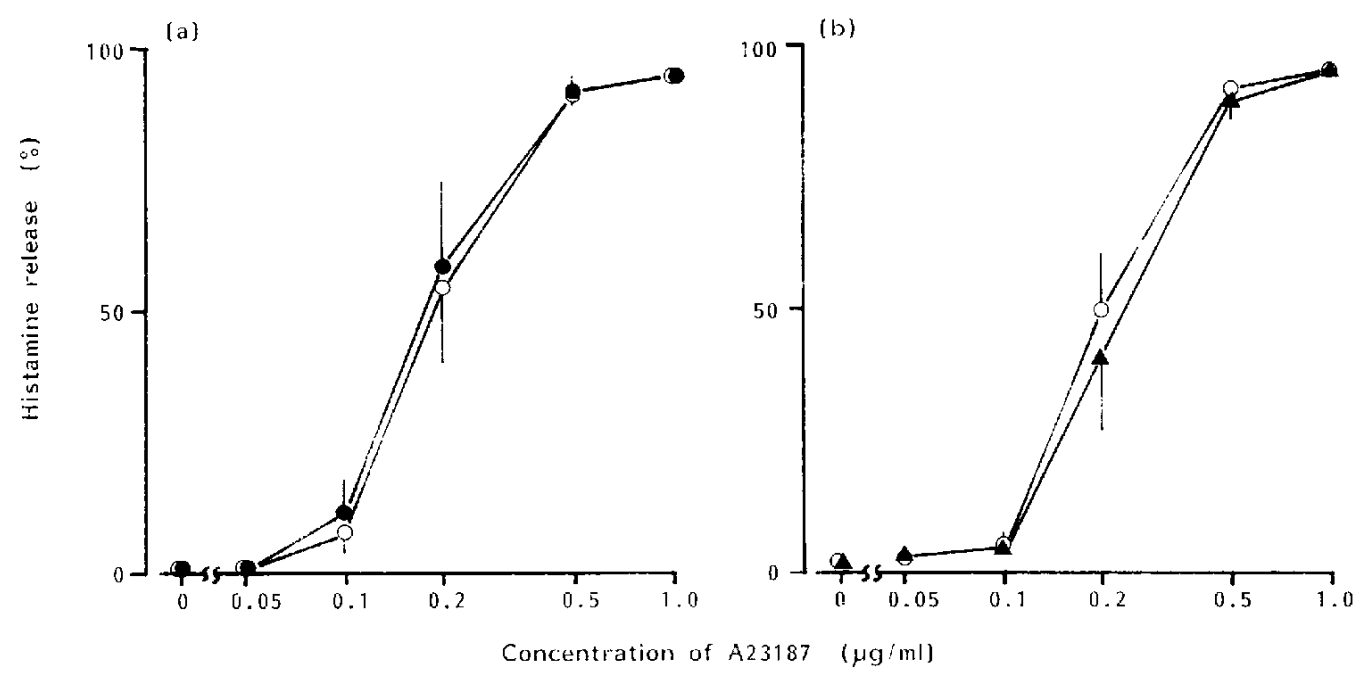

Fig. 5. Effect of HSR-6071 (a) and DSCG (b) on A23187-induced histamine release from rat peritoneal exudate cells. Each point represents the mean+S.E.M. of 3 experiments. Total histamine contents: $2.54 \pm 0.30 \mathrm{fg} / 10^{5}$ mast cells. (O) $10^{-7} \mathrm{M} \mathrm{HSR}-6071$, (A) $10^{-5} \mathrm{M} \mathrm{DSCG,} \mathrm{(O)} \mathrm{control.}$ 
but rather enhanced at a high concentration of $10^{-4} \mathrm{M}$ (data not shown).

Effects on compound 48/80-, A23187induced and spontaneous histamine release from PEC: Figure 4 illustrates the inhibitory effects of HSR-6071, DSCG, tranilast and amlexanox on the histamine release calused by $0.1 \mu \mathrm{g} / \mathrm{ml}$ of compound $48 / 80$, which ranged from $25.0 \pm 0.1$ to $34.1 \pm 2.7 \%$ in the different experiments. The IC50 values of HSR-6071, DSCG, tranilast and amlexanox were calculated to be $6.0 \times 10^{-9}, 1.0 \times 10^{-6}$, $4.2 \times 10^{-5}$ and $2.7 \times 10^{-8} \mathrm{M}$, respectively. On the other hand, A23187 $(0.05$ to $1 \mu \mathrm{g} / \mathrm{ml})$ induced histamine release was unaffected by HSR-6071 $\left(10^{-7} \mathrm{M}\right)$ and DSCG $\left(10^{-5} \mathrm{M}\right)$ (Fig. 5). In addition, spontaneous histamine release from mast cells was unaffected by $10^{-4}$ M of HSR-6071 (data not shown).

\section{Discussion}

The effect of HSR-6071 on the $\operatorname{lgE}$ mediated PCA in rats was investigated as compared with those of other antiallergic agents. HSR-6071 was effective not only by i.v. but also by p.o. administration. The most potent inhibition with the agent was observed when it was given p.o. $5 \mathrm{~min}$ before the antigen challenge, indicating the rapid absorption of the agent through the gastrointestinal tract. This speculation was proved by determining the plasma concentration of HSR6071 after p.o. administration (O. Nagata et al., unpublished data). In addition to the rapid demonstration of the effect, it seems worthy to note that the inhibitory effect of this agent was detectable 60 min after p.o. application. By both i.v. and p.o. routes, the inhibitory activity of HSR-6071 was the most potent among the compounds tested herein (Table 1).

Next, whether or not SHR-6071 possesses antagonistic action to histamine, serotonin or bradykinin was investigated. HSR-6071 unlike ketotifen at doses or concentrations sufficient to inhibit PCA or to inhibit allergic histamine release failed to modify the agonists-induced increase in vascular permeability or contractile response of the isolated guinea pig ileum to histamine. acetylcholine and serotonin. These results indicate that the potent inhibition of PCA with HSR-6071 might not be based on the antagonistic action of the agent to histamine. serotonin, acetylcholine or bradykinin. As to ketotifen, this agent markedly inhibited the increased vascular permeability caused by histamine. serotonin or bradykinin and the contractile responses of the isolated guinea pig ileum to histamine and serotonin. The antagonistic action of ketotifen was most prominent towards histamine and was in a non-competitive manner (8). In this respect, the pharmacological properties of HSR-6071 differ from those of ketotifen, which may inhibit PCA through its antagonistic action on chemical mediators, since ketotifen had no inhibitory effect on the lgE-mediated histamine release at $10^{-5} \mathrm{M}$ or less, but rather augmented the histamine release at a high concentration of $10^{-4} \mathrm{M}$.

The lgE-mediated histamine release from PEC was more or less inhibited by all agents tested except for ketotifen. The activity of HSR-6071 in inhibiting histamine release was approximately 700 times more potent than DSCG. The potency of the agents other than HSR-6071 determined in the present experiments coincided well with that reported in the previous reports $(7,11,12)$. On the other hand, HSR-6071 was without effect on the A23187-induced and spontaneous histamine release, although the agent inhibited the histamine release induced by the low concentration of compound 48/80.

All these results indicate that HSR-6071 possesses a potent antiallergic activity and that the inhibition of PCA by HSR-6071 may be due to the suppression of chemical mediators release from mast cells.

Detailed pharmacological and toxicological properties of HSR-6071 will be reported elsewhere.

Acknowledgements: The authors thank M. Suzuki and $M$. Tanaka for technical assistance in preparing this manuscript.

\section{References}

1 Kusner, E.T., Dubnick, B. and Herzig, D.J.: The inhibition by disodium cromoglycate in vitro of anaphylactically induced histamine release from rat peritoneal mast cells. J. Pharmacol. Exp. Ther. 184, $4 \mathbf{i}-46$ (1973)

2 Cox, J.S.G., Beach, J.E., Blair, A.M.J.N., Clarke, 
A.J., King, J., Lee, T.B., Loveday, D.E.E., Moss, G.F., Orr, J.S.C., Ritchie, J.T. and Sheard, P.: Disodium cromoglycate (Intal). Adv. Drug Res. 5. \$15-196(1970)

3 Cox, J.S.G.: Disodium cromoglycate, mode of action and its possible relevance to the clinical use of the drug. Br. J. Dis. Chest 65, 189-204 (1971)

4 Suschitzky, J.L. and Sheard, P.: The search for antiallergic drugs for the treatment of asthmaproblems in firding a successor to sodium cromoglycate. Prog. Med. Chem. 21, 1-61 (1984)

5 Koda, A., Nagai, H., Watanabe, S., Yanagihara, $Y$. and Sakamoto, K.: Inhibition of hypersensitivity reactions by a new drug. N-(3',4'-dimethoxycinnamoyl)anthranilic acid $\left(\mathrm{N}-5^{\prime}\right)$. J. Allergy Clin. Immunol. 57, 396-407 (1976)

6 Azuma, H., Banno, K. and Yoshimura, T.: Pharmacological properties of $\mathrm{N}-\left(3^{\prime}, 4^{*}\right.$-dimethoxycinnamoyl)anthranilic acid $\left(\mathrm{N}-5^{\prime}\right)$, a new antiatopic agent. $\mathrm{Br}$. J. Pharmacol. 58, 483-488 (1976)

7 Nakazawa, M., Yoshimura, T., Naito, J. and Azuma, H.: Pharmacological properties of $\mathrm{N}$ $\left(3^{\prime}, 4^{\prime}\right.$-dimethoxycinnamoyl)anthranilic acid ( $N$ $\left.5^{\prime}\right)$, a new antiatopic agent. (5). Influence of $\mathrm{N}-5^{\prime}$ on histamine release from rat peritoneal exudate cells. Folia Pharmacol. Japon. 74, 483490 (1978) (Abs. in English)

8 Martin, U. and Romer, D.: The pharmacological properties of a new orally active antianaphylactic compound: ketotifen, benzocycloheptathiophene. Arzneimittelforschung 28, 770-782 (1978)

9 Tasaka, K. and Akagi, M.: Anti-allergic properties of a new histamine antagonist, 4-(p- chlorobenzyl) - 2 - ( $\mathrm{N}$ - methyl - perhydroazepinyl(4)) - 1 - (2H) -phthalazine hydrochloride (Azelastine). Arzneimittelforschung 29, 488-493 (1979)

10 Ohmori, K., Ishii, H., Naito, M., Shuto, K. and Nakamizo, N.: Pharmacological studies on oxatomice (KW-4354). (7) Antagonistic effects on chemical mediators. Folia Pharmacol. Japon. 81, 399-409 (1983) (Abs. in English)

11 Saijo, T., Kuriki, H., Ashida, Y., Makino, H. and Maki, Y.: Mechanism of the action of amoxanox (AA-673), an orally active antiallergic agent. !nt. Arch. Allergy Appl. Immunol. 78, 43-50 (1985)

12. Yamada, N., Takahashi, K., Endoh, K. and Arai, $Y$.: Inhibitory effects on the release of mediators from rat peritoneal exudate cells and antagonistic effect against mediators of MY-5116 and other anti-allergic agents. Folia Pharmacol. Japon. 88, 229-237 (1986) (Abs. in English)

13 Takahashi, K. and Shono, T.: Effects of My-5116 on PCA reaction and on the histamine release from peritoneal cells induced by antigen antibody reactions. Folia Pharmacol. Japon. 87, 29-39 (1986) (Abs. in English)

14 Tada, T. and Okumura, K.: Regulation of homocytotropic antibody formation in the rat. I. Feed back regulation by passively administered antibody. J. Immunol. 106, 1002-1011 (1971)

15 Katayama, S., Shionoya, H. and Ohtake, S.: A new method for extraction of extravasated dye in the skin and the influence of fasting stress on passive cutaneous anaphylaxis in guinea pigs and rats. Microbiol. Immunol. 22, 89-101 (1978)

16 Shore, P.A., Burkhalter, A. and Cohn, V.H., Jr.: A method for the fluorometric assay of histamine in tissues. J. Pharmacol. Exp. Ther. 127, 182-186 (1959) 